\title{
Monitoring of reinforced concrete short ties with the acoustic emission technique
}

\author{
Djillali Mezhoud ${ }^{2}$, Jacqueline Saliba ${ }^{1, *}$, \\ ${ }^{1}$ Université de Bordeaux, UMR 5295, Institut de Mécanique et d'Ingénierie (I2M), Département de \\ Génie Civil et Environnemental (GCE), 33000 Bordeaux, France \\ ${ }^{2}$ Laboratoire de Génie de la Construction et Architecture (LGCA), Faculté de Technologie, Université \\ de Bejaia, 06000 Bejaia, Algérie.
}

\begin{abstract}
Cracking in Reinforced Concrete (RC) structures may impact their durability and their structural integrity. Cracking is mainly influenced by stress distribution along the interface between steel and concrete. Thus, quantitative evaluation of steel-concrete bond, which is responsible of transferring load from steel bar to the surrounding matrix, and its effect on fracture properties is of major important. An experimental investigation on $\mathrm{RC}$ ties is reported in this paper. Tensile tests have been conducted on cubic specimens with different high adhesion reinforcement diameters. Those tests have been monitored continuously using the Acoustic Emission (AE) technique for a better evaluation of the damage process. The results show a good correlation between the load and the AE activity. AE signals with different characteristics have been observed during the different fracture stages. Parameters such as duration and energy increased with the loading level and can be used as indicators to detect the macrocracking of concrete. A parametric analysis is performed between average frequency and RA value. Ib-value of AE hits has been also investigated and decreases to 0.12 prior to the first macro crack.
\end{abstract}

\section{Introduction}

Many bridges and RC structures collapsed during the last years due to aging. Thus, the implementation of advanced health monitoring system is necessary to provide advance warning of the structures distress, characterize the damage state and select a proper repair methodology to avoid such collapse. The Structural Health Monitoring (SHM) by means of non-destructive techniques as the $\mathrm{AE}$ technique offers the potential to identify structural distress that can serve as an indicator of damage and allows the prediction of the residual life of the structure [1]. The structural behavior of RC is mainly affected by the bond between the reinforcement and the concrete [2]. The bond-slip interaction between reinforcement and concrete is characterized by three main components: chemical adhesion, mechanical interaction, and friction. For low bond stress values, the chemical adhesion

* Corresponding author: jacqueline.saliba@u-bordeaux.fr 
breaks down first and no slip between the reinforcement and the concrete is observed. For higher bond stress values, the limited wedging action of the lugs cause transverse microcracks and allow the bar to slip. Note that the bond behavior is affected by the cover and the confinement [3]. A recent study conducted by Mezhoud \& al. [4] proposed new relationships for the bond slip law based on pull-out tests and the behavior of short tie rods. However, few studies analysed the AE response corresponding to the degradation mechanisms between steel and concrete bond. This analysis allows a better real time monitoring of the fracturing stage of RC structures in order to maintain their sustainability [5]. The AE technique can also provide useful information about the location of defects and damage characteristics [6].

First, the materials, the experiments and the tensile test conditions are presented. Then, the effect of reinforcement in terms of AE output is investigated and a detailed analysis of $\mathrm{AE}$ signal parameters with respect to bond stress is proposed in order to characterize the different phases of failure.

\section{Experimental program}

\subsection{Materials properties}

The concrete was cast using ordinary Portland cement, water, river sand and coarse aggregate with a maximum grain size of $15 \mathrm{~mm}$. The water to cement ratio is equal to 0.5 . The mix proportion of concrete is shown in table 1 .

Table 1. Concrete mixture proportions

\begin{tabular}{|c|c|}
\hline Constituents & $\begin{array}{c}\text { Dosage } \\
\left(\mathbf{k g} / \mathbf{m}^{\mathbf{3}}\right)\end{array}$ \\
\hline Gravel 5/15 & 1148.07 \\
\hline Sand 0/5 & 629.34 \\
\hline Cement & 400 \\
\hline Water & 202.17 \\
\hline
\end{tabular}

Compression and tensile tests have been conducted on prismatic $\left(15 \times 15 \times 15 \mathrm{~cm}^{3}\right)$ and cylindrical $\left(11 \times 22.5 \mathrm{~cm}^{3}\right)$ concrete specimens respectively. Hot rolled ribbed commercial bars have been used with a nominal diameter of 8,12, 14 and $16 \mathrm{~mm}$. Table 2 presents the mechanical properties of concrete and steel bar.

Table 2: Properties of concrete and steel bar

\begin{tabular}{|c|c|c|c|}
\hline Concrete & $\begin{array}{l}\text { Mean } \\
\text { value }\end{array}$ & Steel bar & Mean value \\
\hline $\mathbf{f t}(\mathbf{M P a})$ & 2.6 & $\mathbf{E s}$ & $200 \mathrm{GPa}$ \\
\hline $\mathbf{f c}(\mathbf{M P a})$ & 33.7 & $\mathbf{f y}$ & $500 \mathrm{MPa}$ \\
\hline
\end{tabular}

The adhesion between steel and concrete depends highly on the geometrical characteristics of the ribs considering the height h1, the spacing e1, the angle of the ribs $\alpha 1$ (45 to $50^{\circ}$ ) and their inclination $\alpha 2\left(45\right.$ to $\left.50^{\circ}\right)$ (figure 1$)$. 


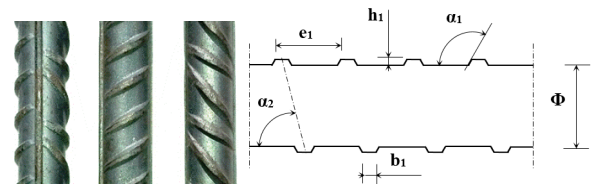

\begin{tabular}{|c|c|c|c|c|}
\hline $\begin{array}{c}\Phi \\
(\mathrm{mm})\end{array}$ & $\begin{array}{c}\mathrm{h}_{1} \\
(\mathrm{~mm})\end{array}$ & $\begin{array}{c}\mathrm{b}_{1} \\
(\mathrm{~mm})\end{array}$ & $\begin{array}{c}\mathrm{e}_{1} \\
(\mathrm{~mm})\end{array}$ & $\begin{array}{c}\mathrm{A}_{\mathrm{s}} \\
\left(\mathrm{mm}^{2}\right)\end{array}$ \\
\hline 8 & 0.7 & 0.9 & 5.3 & 50.3 \\
\hline 12 & 1 & 1.2 & 7.2 & 1.13 \\
\hline 14 & 1.1 & 1.4 & 8.4 & 1.154 \\
\hline 16 & 1.2 & 1.6 & 9.6 & 2.01 \\
\hline
\end{tabular}

Fig. 1. a) Ribbed steel bar used b) Geometric characteristics of the ribs c) Geometric characteristic values of the ribs

\subsection{Tensile tests on reinforced concrete ties}

In order to study the effect of bar diameter on the state of maximum mobilization of the adhesion between steel and concrete, tensile tests on RC ties have been carried out on samples with different bar diameters and lengths considering the same concrete cross section $10 \times 10 \mathrm{~cm}^{2}$. For each bar diameter, three lengths have been considered: 250,450 and $650 \mathrm{~mm}$. Tensile tests have been conducted up at a concrete age of 28 days to the yielding of the bars (figure 2). The AE technique has been also applied in parallel during the loading of reinforced concrete ties.

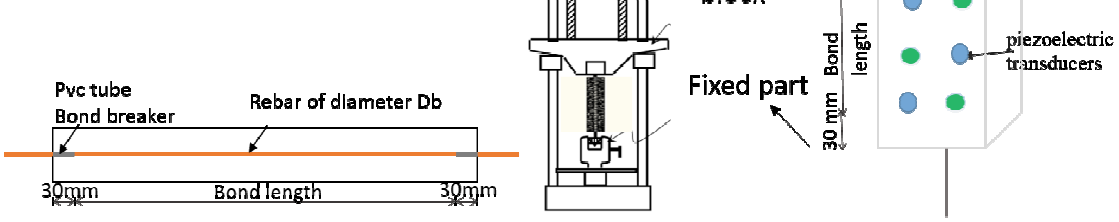

Fig. 2. a) Specimen's dimension, b) Schematic diagram of the experimental arrangement of the tensile test c) AE sensor arrangement

\subsection{Acoustic emission technique}

The AE system consists of an eight channel AE Win system, a general-purpose interface bus (PCI-DISP4) and a PC for data storage analysis. Six piezoelectric transducers have been used to convert the mechanical waves to electrical signals. Piezoelectric sensors have a resonant frequency of $150 \mathrm{kHz}$. Tensile tests have been monitored by a three dimensional positioning. The sensors are placed on both free frontal surfaces of the sample with silicon grease as the coupling agent (figure $2 \mathrm{c}$ ). The detected signals have been amplified with a $40 \mathrm{~dB}$ gain differential amplifier. The signal detection threshold has been set at a value of about $35 \mathrm{~dB}$ to overcome the background noise [23]. The acquisition system has been calibrated before each test using a pencil lead break procedure HSU-NIELSEN (Norme NF EN 1330). The effective velocity is equal to $3800 \mathrm{~m} / \mathrm{s}$. Signal descriptors such as rise time, counts, energy, amplitude, average frequency, duration and counts to peak have been captured and calculated by AEwin system. 


\section{Tensile tests}

\subsection{Monitoring of short ties with the AE technique}

Tensile test on RC ties is one of the most suitable tests for observing the propagation of cracks in RC structures. As the specimen is subjected to pure tension loading, the effects of the steel and concrete bond, such as stress distribution, tension stiffening reduction and concentration of forces at some local points can be observed. Tensile tests have been continuously monitored with the AE technique. Figure 3 shows the evolution of the applied load in correlation with the cumulative number of $\mathrm{AE}$ hits and the duration of $\mathrm{AE}$ hits matched on a common time scale for reinforced concrete specimen with HA8 and a length of $650 \mathrm{~mm}$. Monitoring of short ties with the AE technique allows to distinguish the different phases of damage in RC structures that can be decomposed in three phases. During the elastic phase, the elongation of short ties is progressive with the applied load. At the ends of the tie rod, the load is only supported by the steel rod. The load is then transferred to both materials along a transfer length until the load is perfectly distributed. Few AE signals are first detected due to the rupture of the chemical adhesion between concrete and steel during the elastic linear phase, then AE hits increased with loading due to the generation of micro-cracking in concrete. Stresses in concrete increases with the load until the stress is equal to the maximal strength of concrete where the tensile strength is week considering the heterogeneity of concrete. The number AE hits increases suddenly indicating the development of a macro crack; this is accompanied with the generation of $\mathrm{AE}$ hits of high duration and energy and a decrease in structural rigidity. When RC ties are cracked, stresses are equal to zero locally and the load is totally supported by steel. On both side of the crack, the efforts are again progressively transferred to concrete due to bond adhesion. The stress increases in concrete far from the crack until the stresses are again homogeneous in both materials. The number of AE hits continues to increase indicating the micro-cracking of concrete until the development of secondary cracks along the tie rod in the case of HA16. A stabilized crack pattern is attained when the length of a single part is no longer sufficient to allow the concrete strain to reach the failure value in tension and the behavior of the tie rod is governed by the behavior of the steel. The number of AE hits increases with a higher rate at the end indicating that the rebar has attained the plastic stress. This phase is accompanied with AE hits of higher duration.

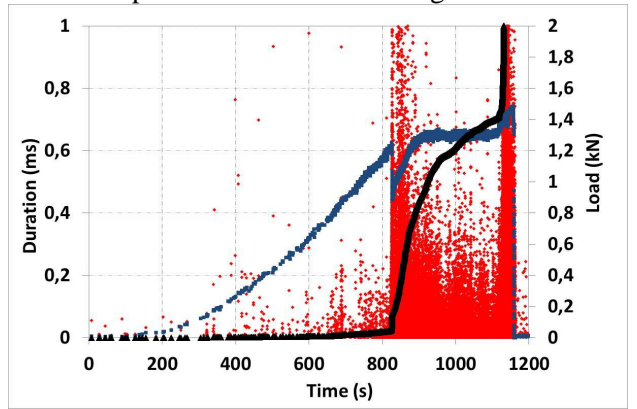

Fig. 3. Correlation between the load and the cumulated number and the duration of AE signals for reinforced concrete specimen with HA8 and a length of $650 \mathrm{~mm}$.

Note here that in function of the bar diameter and the length of the ties, ties without or with one, two or three main cracks have been observed during tensile tests.

The cracking modes of reinforced concrete short ties have been also studied by evaluating the RA value and the average frequency. RA value is defined as the ratio of the rise time by 
the amplitude while the average frequency is defined as the ratio of threshold crossing by the duration. Based on those two parameters, cracks can be classified into tensile and shear cracks. Figure 4 shows the plot of the average frequency versus the RA value for reinforced concrete specimens with HA8 and a length of $650 \mathrm{~mm}$ during three different stages. The stage I corresponds to micro-cracking that occurs before the nucleation of the first macrocrack; the stage II corresponds to the stage of apparition of the first macro-crack; and stage III is the zone between the cracking of concrete and the steel yielding. The results show that during the stage I, tensile cracks dominated with low RA values. During the stage II, a transition phase occurred with higher RA values indicating shear cracks and friction at the steel-concrete or concrete-concrete interface. At the stage III, shear cracks dominated.

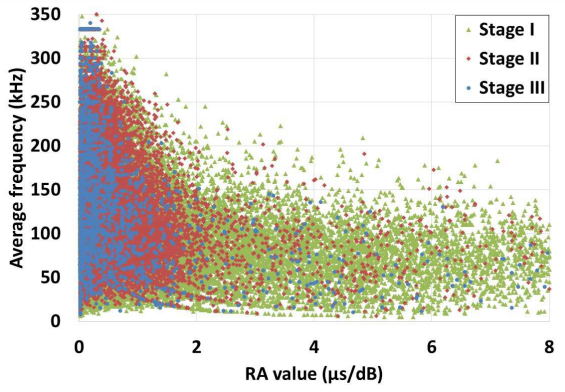

Fig. 4: Relation between average frequency and RA value for reinforced concrete specimens with HA8 and a length of $650 \mathrm{~mm}$.

\subsection{Evolution of Ib-value}

The AE peak amplitude is related to the magnitude of the fractures developed during tensile loading. To determine the overall fracture quantitatively on basis of peak amplitude, the bvalue originated from seismology is performed. It is defined as a negative gradient of the seismic magnitude distribution.

$$
I b=\frac{\log _{10} N\left(\mu-\alpha_{1} \sigma\right)-\log _{10} N\left(\mu+\alpha_{2} \sigma\right)}{\left(\alpha_{1}+\alpha_{2}\right) \sigma}
$$

Where $\sigma$ is the standard deviation of the amplitude distribution, $\mu$ is the mean value of the amplitude distribution, $\alpha_{1}$ is the coefficient related to the smaller amplitude and $\alpha_{2}$ is the coefficient related to the fracture level. $\alpha_{1}$ and $\alpha_{2}$ are constants and are equal to 0 and 1 respectively. Recently, statistical values of the amplitude distributions have been incorporated to the b-value in order to apply it for fracture evaluation in civil engineering materials. If small-scale fractures are superior to large-scale fractures, the Ib-value tend to increase, in the contrary if large-scale fractures are superior to small-scale fractures, the Ibvalue tends to decrease.

The Ib-value has been calculated using the peak amplitudes of 100 successive hits. Figure 5 shows the evolution of the improved Ib-value. The Ib-value is equal to approximately 0.25 during the primary stage indicating small-scale fracturing and then decreases during the secondary phase and drops quickly to approximately 0.12 prior to the nucleation phase of crack and the slip of the rebar and then grow quickly and fluctuates with lower Ib-value during the failure stage of concrete indicating large scale fractures and continue to occur indicating the fracture of concrete until the rupture of the steel bar with an Ib-value of 0.05 . 


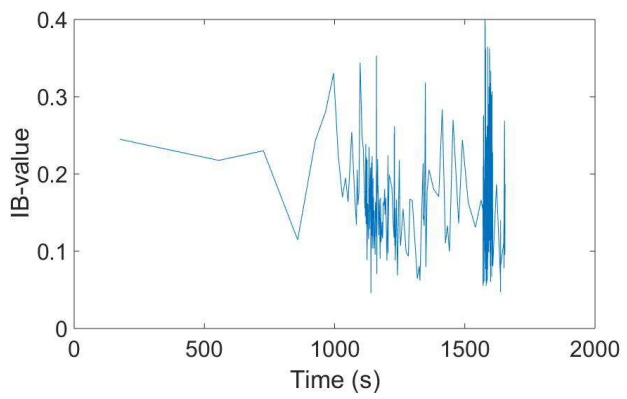

Fig. 5. Evolution of Ib-value

\section{Conclusions}

This study allows to analyse the characteristics of AE hits generated during tensile tests of $\mathrm{RC}$ ties in order to investigate the cracking response of RC structures in terms of AE output data and the influence of the reinforcement ratio. The AE activity is highly correlated to different degradation phases of steel-concrete bond. AE analysis enabled the detection of the early stage of bond deterioration, the development of micro-cracking and the identification of the macro-cracking prior to the plastic deformation of steel. The values of duration, AE energy, amplitude and the cumulative number of AE hits increase as the level of damage increases. The results show also that seismic Ib-values could be an indicator of concrete rebar slip and crack nucleation.

Numerical simulations will be realized in the future for a better understanding of the influence of different properties and parameters on steel-concrete bond and cracking of RC structures.

\section{References}

1. O. Yapar, P.K. Basu, P. Volgyesi, A. Ledeczi, Strcutural health monitoring of bridges with piezoelectric AE sensors. Engineering Failure Analysis. 56 (2015) 150-169.

2. L. Jason, A. Torre-Casanova, L. Davenne, X. Pinelli, Cracking behavior of reinforced concrete beams : experiment and simulations on the numerical influence of the steelconcrete bond. International Journal of Fracture. 180 (2013) 243-260.

3. G.A Plizzari, M.A. Deldossi, S. Massimo, Experimental study on anchored bars in R.C. elements with transverse reinforcement. Materials and Structures. 29 (1996) 534542.

4. D. Mezhoud, Y. Bouafia, M. Saad, J. Saliba, Bond-slip law and short tie behavior without main cracks. Journal of Adhesion Science and Technology, https://doi.org/10.1080/01694243.2018.1432235

5. M.N. Noorsuhada, An overview on fatigue damage assessment of reinforced concrete structures with the aid of acoustic emission technique. Construction and Building Materials. 112 (2016) 424-439.

6. Carpinteri A., Lacidogna G., Pugno N., Structural damage diagnosis and life-time assessment by acoustic emission monitoring. Engineering Fracture Mechanics. 74 (2007) 273-289. 